\title{
CULTIVATION OF CORN UNDER SALINE SOIL RECLAMATION
}

\author{
Chingizkhon Vali ugli Toshpulatov \\ Assistant of the Department of Farming and Land \\ Reclamation, \\ Tashkent State Agrarian University, \\ Tashkent, \\ Uzbekistan
}

\author{
Ikrom Abdukarimovich Rakhmonov \\ Senior Teacher of the Department Soil Science, \\ Gulistan State University, \\ Gulistan, \\ Uzbekistan
}

\author{
Botir Burievich Tukhtashev \\ Candidate of Agricultural Sciences, \\ Docent of the Department of Farming and Land \\ Reclamation, \\ Tashkent State Agrarian University, \\ Tashkent, \\ Uzbekistan
}

\section{Bakhodir Toshboevich Mavlonov \\ Candidate of Agricultural sciences,} Docent of the Department Plant Science and Animal Feed Production, Samarkand Veterinary Medicine Institute, Samarkand, Uzbekistan

\begin{abstract}
To cultivate field crops and increasing their salinity resistance under saline soil condition has become the prior issue. It is important to study the technology of care for each field crop based on the specific soil and climatic conditions. It is very essential to study the advanced technologies to increase the salinity of corn in these soils. In the condition of less saline soils, the green mass of the produced corn was $669.9 \mathrm{c} / \mathrm{ha}$ and dry mass constituted $169.6 \mathrm{c} / \mathrm{ha}$ while was in average saline soil this indicates were $312.7 \mathrm{c} / \mathrm{ha}$ and $95.00 \mathrm{c} / \mathrm{ha}$ relatively. Under strong saline soil condition initially 3-4 pieces of corn sprouted per sq. m. and subsequently died of salt exposure.
\end{abstract}

KEYWORDS: corn, less saline, medium saline, salt resistance, sowing time, dense of seedling, green mass, irrigation dynamics.

\section{INTRODUCTION}

A great deal of saline land reclamations have been carried out in the Republic of Uzbekistan.

The measures such as properly usage of saline soils and minimize salt exposure as much as possible in the plant growing process are being elaborated.

The cultivation technology of each field on specific soil and climatic condition basis has been explored.

In the reclamation of saline soils, the corn plays a special role.

The total irrigated area of Syrdarya region is 266,7 thousand hectares $(80 \%)$, and their salinization is various, $39,8 \%$ is less saline, medium salinity soil makes up $30,4 \%, 6,4 \%$ is considered strong saline, $2,7 \%$ of land is severe saline $[1,2]$.
Due to the urgency of the problem, the effective utilization of these lands, the development of technologies for the cultivation of saline- resistant crops in currently water shortage period is an urgent task of today $[3,4]$.

\section{MATERIALS AND METHODS}

The subject and object of the research: The soil of the experimental area is moderately sandy, light grey, saline soils in terms of mechanical composition.

The ground water is located at a depth of 2.0-2.5 $\mathrm{m}$.

In the annual leaching process, the soil is flooded with a water level of 2.5-3.0 th. $\mathrm{m}^{3}$. In order to survey, the farm "White gold Lops Argo" was selected which situated in Ok Oltin district of Syrdarya region. In the 
experiment, the furrow length was $50 \mathrm{~m}$. Each variant was obtained with 8 rows, that was, with one wheel drive $\left(8 \times 60 \mathrm{~cm}=4.8\right.$ meters, $4.8 \times 50$ meters $\left.=240 \mathrm{~m}^{2}\right)$

Thus, the first plot was designed as $240 \mathrm{~m}^{2}$ and the settlement area was $120 \mathrm{~m}^{2}$.

In the experiment the following Argo chemical and water- physical properties of soil were studied.

In spring in order to determine the agrochemical parameters of soil samples from mixed soil layers by 0.30 and $30-50 \mathrm{~cm}$ in contour method were received from 5 points of the experimental soil.

The total humus and its content in these samples was determined by I.M. Tyrin method; nitrogen and phosphorus by I.M. Maltseva and L.N. Gritsenko methods; nitrate nitrogen with the ionometric instrument; active phosphorus by B.P. Machigin and exchange potassium by P.V. Protasav methods.

1. In order to determine the amount of NRK their common and active forms of humus content in the layer of $0-30 \mathrm{~cm}$ and $30-50 \mathrm{~cm}$ before soil sowing the samples were taken and transferred to the laboratory for analysis according to tillage and below tillage layers of soil.

2. The soil capacity weight was defined by irrigation procedures in each $10 \mathrm{~cm}$ layer at depth of 0 $100 \mathrm{~cm}$.

3. The soil water retention parameters were determined by spring irrigation procedures using special cylinders.

4. Limited field moisture capacity was calculated by filling the site with water at the 2 points of the experimental field $[6,7]$.

5. Saline level of the experimental soil - seasonal salt accumulation $(0-100 \mathrm{~cm})$ was determined [5].

\section{RESULTS AND DISCUSSION}

Young sprouts of multi harvested corn were very delicate and very sensitive to stiff soils. Therefore, when the corn sprouted and the plants came out in the rows, treatment began between the rows.

During the growth and development of the corn, the plant was cultivated for three times in a row. The rows were loosened in the first cultivation to a depth of $6-8 \mathrm{~cm}$, and then to a depth of $12-14 \mathrm{~cm}$. A $100 \mathrm{~kg}$ of nitrogen and $30 \mathrm{~kg}$ of phosphorus fertilizer were applied per hectare after the first cultivation,

In the second treatment, $60 \mathrm{~kg}$ of nitrogen and 30 $\mathrm{kg}$ of phosphorus were applied between the rows per hectare. During the third in-row cultivation the soil was fed with $30 \mathrm{~kg}$ of nitrogen per hectare.

So, the corn was given $190 \mathrm{~kg}$ of nitrogen and 60 $\mathrm{kg}$ of phosphorus fertilizer during the growing season.

Cultivation of the corn between the rows was conducted till July. In July inter -row processing stopped. The optimal rate for corn was determined by the soil moisture. The number of irrigations was determined 6 times for the green mass during the growing season, 2 times before each harvest.

Under this irrigation rate, the soil moisture did not fall below $75-80 \%$ of the LFMC (limited field moisture capacity) before corn sprouting. In the vegetation period, the initial watering started when the plant produced 5-6 leaves. This term was on May 28. After 16-18 days, on June 14-16, the second irrigation was carried out.

Irrigation rates increased by $20-25 \%$ due to the fact that the corn grass was still young in the first and second irrigation and the salts in the soil are more likely to destroy the grass. That meant that each irrigation rate was set at $1000-1100 \mathrm{~m}^{3} / \mathrm{ha}$. The corn was harvested 3 times and it was irrigated 2 times between the harvests. The rate of irrigation was set in the LFMC (limited field moisture capacity) and constituted $800-1000 \mathrm{~m}^{3} / \mathrm{ha}$.

Increasing of salinity content in the soil began to manifest itself during the early stages of plant seeds development.

In the cultivation of corn under medium and strong saline soils, first of all, it was necessary to take measures of achieving fully germination of seedlings before they were evenly salted.

Therefore, it is necessary to sow the corn seeds early and to get a full seedling. It is not doubtful that the salt content in average saline soils led to late formation of seedlings.

In this point, firstly it was observed that the seeds did not sprout in cases of severe saline soils, where the salt content was $0.5-2.0 \%$ of the dry weight of the soil, and secondly, it resulted in dying of the young seedlings at the early stages.

This affects the plant's further growth and development.

In experiment's first repetition a month after sowing corn, or $15^{\text {th }} 16^{\text {th }}$ day of germination, the plant height was around $19.4 \mathrm{~cm}$, and $5^{\text {th }}$ leaf began to grow, the growth rate in subsequent development periods was intensive, in the calculations made in early July the height of the plant was $98.7 \mathrm{~cm}$ tall and their leaves were 13.5 pcs. respectively, and at last on August 1 in the third time that biometric calculations showed the plant's height to be $183.9 \mathrm{~cm}$ and the number of leaves was 15.9 pcs.

The similar data on the corn growth and development were obtained for the remain repetitions.

However, in the fourth repetition, there were significant differences in the height and the number of leaves on biometric calculations which were carried out three times.

This can be explained by the partial destroying of agro-technical measures undertaken during the development of the plant.

Generally, according to $4^{\text {th }}$ repetition in the plant's biometric calculations of

July 1 , the height of the plants was $86,4 \mathrm{~cm}$ and the number of leaves was 9.6, while in the calculations at the end of the vegetation the indications were 166.7 and 12.0 respectively. 
Table 1

Biometric calculations in corn.

(The corn was sown 1.05.19)

\begin{tabular}{|c|c|c|c|c|c|c|c|}
\hline \multirow[t]{3}{*}{ № } & \multirow{3}{*}{ Repetitions } & \multicolumn{6}{|c|}{ In the area of less saline soils } \\
\hline & & \multicolumn{2}{|c|}{ 01.06.19 } & \multicolumn{2}{|c|}{01.07 .19} & \multicolumn{2}{|c|}{ 01.08.19 } \\
\hline & & Plant height & $\begin{array}{l}\text { Number of } \\
\text { leaves }\end{array}$ & Plant height & $\begin{array}{c}\text { Number of } \\
\text { leaves }\end{array}$ & $\begin{array}{l}\text { Plant } \\
\text { height }\end{array}$ & $\begin{array}{l}\text { Number } \\
\text { of leaves }\end{array}$ \\
\hline 1 & 1-repetition & 19.4 & 4.6 & 98.7 & 13.5 & 183.9 & 15.9 \\
\hline 2 & 2- repetition & 17.6 & 4.4 & 95.4 & 13.0 & 179.5 & 14.3 \\
\hline 3 & 3- repetition & 15,4 & 3.8 & 90.5 & 11.6 & 170.6 & 13.2 \\
\hline 4 & 4- repetition & 13.7 & 3.0 & 86.0 & 9.8 & 166.7 & 12.0 \\
\hline \multirow[t]{2}{*}{5} & $\begin{array}{l}\text { On } 4 \text { repetition: } \\
\text { medium }\end{array}$ & $68.1: 4=17.0$ & $15.8: 4=3.95$ & $373.6: 4=93.4$ & $49.9: 4=12.5$ & $\begin{array}{l}703.7: 4 \\
=175.8\end{array}$ & $\begin{array}{l}56.4: 4 \\
=14.1\end{array}$ \\
\hline & & \multicolumn{6}{|c|}{ In the area of medium saline soils } \\
\hline 1 & 1- repetition & 15.5 & 4.0 & 78.5 & 10.1 & 158.0 & 13.0 \\
\hline 2 & 2-repetition & 16.0 & 3.5 & 79.3 & 9.5 & 145.5 & 12.8 \\
\hline 3 & 3- repetition & 14.6 & 3.0 & 81.0 & 8.5 & 141.7 & 12.1 \\
\hline \multirow[t]{3}{*}{4} & 4- repetition & 14.0 & 3.1 & 74.5 & 9.2 & 144.6 & 11.6 \\
\hline & $\begin{array}{l}\text { On } 4 \text { repetition: } \\
\text { medium }\end{array}$ & $60.1: 4=15.0$ & $13.6: 4=3.4$ & $313.3: 4=78.2$ & $37.3: 4=9.3$ & $\begin{array}{l}589.8: 4 \\
=147.4\end{array}$ & $\begin{array}{l}49.5: 4 \\
=12.3\end{array}$ \\
\hline & & \multicolumn{6}{|c|}{ In the area of severe saline soils } \\
\hline 1 & 1- repetition & 11.0 & 2.1 & 32.0 & 3.9 & 32.0 & 3.9 \\
\hline 2 & 2- repetition & 6.5 & 2.6 & 26.5 & 5.8 & 26.5 & 5.8 \\
\hline 3 & 3- repetition & 8.6 & 3.3 & 33.7 & 7.1 & 33.7 & 7.1 \\
\hline 4 & 4- repetition & 10.0 & 4.9 & 47.8 & 6.3 & 47.8 & 6.3 \\
\hline & $\begin{array}{l}\text { On } 4 \text { repetition: } \\
\text { medium }\end{array}$ & $36.1: 4=9.0$ & $12.9: 4=3.2$ & $140.0: 4=35.0$ & $23.1: 4=5.7$ & $\begin{array}{c}140.0: 4 \\
=35.0\end{array}$ & $\begin{array}{c}23.1: 4 \\
=5.7\end{array}$ \\
\hline
\end{tabular}

According to studies that there was a slight difference in biometric calculations of corn under less saline and moderately saline soils.

In particular, the effect of salt was obvious in the early development of the plant and it negatively impacted on subsequent development phases.

Specifically, in average saline soils, the plant height was $15.0 \mathrm{~cm}$ in biometric calculations of 1.06.19, and $78.2 \mathrm{~cm}$ in 1.07 .19 , and finally it was $146.6 \mathrm{~cm}$ in 1.08.19, and plant height was detected to be weaker than the plants which were cultivated in less saline soil. This certainly had an impact on the productivity.

Calculation of green mass and hay yield of corn.

In calculating the yield of corn, the plants which were at the same linear meter $(16.6 \mathrm{l} \mathrm{m})$ harvested and weighed in a wet condition. The wet weight and dry mass of corn harvested from the field and they were also calculated. Initially the plant was calculated at $16.61 . \mathrm{m}$. (linear meter). This figure was the same in all plots and made up a total 250 pieces of plants. Then the green mass and the dry mass of the plant in this area was calculated separately. 
Table 2

Calculation of corn green mass and dry silage yield

(on the second harvesting)

\begin{tabular}{|c|c|c|c|c|c|c|c|}
\hline \multirow[t]{2}{*}{ № } & \multirow[t]{2}{*}{ Repetitions } & \multirow{2}{*}{$\begin{array}{c}\text { Number of } \\
\text { plants, per } \\
1 \text { ha }\end{array}$} & \multirow{2}{*}{$\begin{array}{c}\text { Number of } \\
\text { plants at } \\
16,6 \mathrm{l} . \mathrm{m} .\end{array}$} & \multicolumn{2}{|c|}{$\begin{array}{c}\text { Productivity, 16,6 linear } \\
\text { meter, } \mathrm{g}\end{array}$} & \multicolumn{2}{|c|}{ Productivity, c/ha. } \\
\hline & & & & Green mass & Dry mass & Green & Dry \\
\hline \multicolumn{8}{|c|}{ In the area of less saline soils } \\
\hline 1. & 1-repetition & 500.000 & 250 & 36.000 & 9000 & 722.3 & 180.5 \\
\hline 2. & 2-repetition & 500.000 & 250 & 34.500 & 8500 & 692.7 & 173.1 \\
\hline 3. & 3- repetition & 500.000 & 250 & 32.200 & 8100 & 643.3 & 160.8 \\
\hline 4. & 4- repetition & 500.000 & 250 & 30.950 & 7500 & 620.4 & 155.1 \\
\hline & $\begin{array}{c}\text { On } 4 \\
\text { repetition: } \\
\text { medium: }\end{array}$ & 500.000 & 250 & $\begin{array}{l}133650: 4 \\
=33412\end{array}$ & $\begin{array}{l}33100: 4 \\
=8275\end{array}$ & $\begin{array}{l}2678.7: 4 \\
=669.6\end{array}$ & $\begin{array}{c}678.5: 4= \\
169.6\end{array}$ \\
\hline & Medium: & 500.000 & 250 & 33412 & 8275 & 669.6 & 169.6 \\
\hline \multicolumn{8}{|c|}{ In the area of medium saline soils } \\
\hline 1 & 1-repetition & 500.000 & 250 & 23750 & 2850 & 285 & 71.5 \\
\hline 2 & 2-repetition & 500.000 & 250 & 24600 & 3050 & 305 & 96.4 \\
\hline 3 & 3- repetition & 500.000 & 250 & 25400 & 3210 & 321 & 101.5 \\
\hline 4 & 4- repetition & 500.000 & 250 & 26480 & 3400 & 340 & 112.6 \\
\hline & $\begin{array}{c}\text { On } 4 \\
\text { repetition: } \\
\text { medium: }\end{array}$ & & & $\begin{array}{l}100230: 4 \\
=25057.5\end{array}$ & $\begin{array}{l}12510: 4 \\
=3127.5\end{array}$ & $\begin{array}{c}1251: 4= \\
312.7\end{array}$ & $\begin{array}{l}382.0: 4 \\
=95.5\end{array}$ \\
\hline & Medium: & & & 25057.5 & 3127.5 & 312.7 & 95.5 \\
\hline
\end{tabular}

The table showed theoretical thickness of plant size at $16.6 \mathrm{l} . \mathrm{m}$ and 1 ha but in practice this seedling was not provided in medium and extreme salinized soils. Also, in the case of heavy salinized soils, the yield data was insufficient to calculate due to lack of sufficient seedlings in practice.

Thus, the wet mass obtained in the 1 st repetition was $36000 \mathrm{~g}$ or $36 \mathrm{~kg}$, the yield from the second repetition was $34,500 \mathrm{~g}$ or $34.5 \mathrm{~kg}$, the wet mass of the third was $32200 \mathrm{~g}$ or $32.2 \mathrm{~kg}$, and finally it was 30950 or $30.9 \mathrm{~kg}$ on the fourth repetition.

Generally, total wet weight which obtained on 4 repetitions was 33412 or $33.4 \mathrm{~kg}$. The dry mass was also calculated in this way. The dry mass yield of the corn (silage) was also calculated in this way. In this case, firstly, the yield and afterwards the average yield was calculated.

So, in the 1st repetition, the yield of silage was $722,3, \mathrm{c} / \mathrm{ha}$, in the second repetition it was $692,7 \mathrm{c} / \mathrm{ha}$, in the third repetition the indicate was $643.3 \mathrm{c} / \mathrm{ha}$, in the fourth repetition it made up $620.4 \mathrm{c} / \mathrm{ha}$. The average yield of corn in the study was $669.6 \mathrm{c} / \mathrm{ha}$. We think that the corn obtained from the average saline soils did not grow well under the influence of salt in the soil.

Therefore, the yield in the moderate saline soils significantly lower than less saline soils and options. In particular, the green corn mass at $16.61 \mathrm{~m}$. was 25057.5 $\mathrm{g}$, it was $8355 \mathrm{c} / \mathrm{ha}$ less than the variant on less saline soils, or the total productivity under these soils constituted $312,7 \mathrm{c} / \mathrm{ha}$.

All crops in the conducted experiments in the case of severe saline soils of Syrdarya region died at the time of early vegetation stage before germinated in the repetitions and variants because of strong sensitive of salt. The yield from most germinated plants was very low. When the phenology of corn which planted under severe saline soils, it was recorded that 650-700 died per 1,000 seeds.

And the sprouted seedlings in the sparsity died under the severe influence of salinity before they reach the next phase.

\section{CONCLUSION}

1. In conclusion, it would be advisable to establish an introduction of saline resistant plants in the saline soils of Syrdarya region and to develop advanced technologies to increase their resistance as well as adaptability in these soils.

2. In this case, produced yield of corn in less saline soils was $6,66,6 \mathrm{c} /$ ha by green mass, whereas in medium salinity soil the productivity was $312,2 \mathrm{c} / \mathrm{ha}$. Under the severe saline soil conditions 3-4 pcs of the corn initially sprouted from each sq.m and then died of salt exposure.

\section{REFERENCES}

1. The Decree of the President of the Republic of Uzbekistan numbered DP-4947, dated on February 7, 2017 "On the strategy of further development of the Republic of Uzbekistan". Collection of Legislation of the Republic of Uzbekistan, 2017, №6, article-70. (In Uzbek).

2. Irrigated soils of Syrdarya and Jizzakh regions. State Committee of the Republic of Uzbekistan 
"Yergeodezkadastr" and State Research Institute of Soil Science and Agrochemistry. (In Uzbek).

3. Vavilov P.P. (1979). Plant science, Moscow, "Kolos", 98 p. (In Russian).

4. Yormatova D. (2000). Plant science, Tashkent, pp. 45-47. (In Uzbek).

5. Nurmatov Sh., Mirzajonov K., Avliyakulov and et al. (2007). Methods of conducting field experiments. Tashkent, $57 \mathrm{p}$.

6. Mirzaev O.F., Hudayberdiyev T.S. (2003). Animal feed production. Andijan Publishing House, 27 p.

7. Yormatova D., Ubaydullaev Sh, Halimov I, Tuhtashev B, Khushvaktova H. (2004). Cultivation of field crops. Tashkent. Publishing house Science, 214 p. (In Uzbek). 